\title{
THE EFFECT OF SOME PLANT GROWTH REGULATORS AND THEIR COMBINATION WITH METHYL JASMONATE ON ANTHOCYANIN FORMATION IN ROOTS OF KALANCHOE BLOSSFELDIANA
}

\author{
Justyna GÓRAJ*, Elżbieta WĘGRZYNOWICZ-LESIAK, Marian SANIEWSKI \\ Research Institute of Horticulture \\ Konstytucji 3 Maja 1/3, 96-100 Skierniewice, Poland \\ Received: May 26, 2014; Accepted: October 10, 2014
}

\begin{abstract}
In this study, we investigated the effect of plant growth regulators (PGRs) - auxins, gibberellin, cytokinin, abscisic acid, brassinosteroid, ethylene and their interaction with methyl jasmonate (JA-Me) applied to roots of the whole plants Kalanchoe blossfeldiana on the accumulation of anthocyanins in roots. The highest stimulation of anthocyanins synthesis was stated with application of JA-Me alone. In response to treatments with the other tested PGRs, the content of anthocyanins in roots of a whole plant was different depending on the concentration of the PGR when being applied alone or together with JA-Me. Auxin, indole-3-acetic acid (IAA) at a concentration of $50 \mathrm{mg} \cdot \mathrm{L}^{-1}$, indole-3-butyric acid (IBA) at $5 \mathrm{mg} \cdot \mathrm{L}^{-1}$ and abscisic acid (ABA) at $10 \mathrm{mg} \cdot \mathrm{L}^{-1}$ induced anthocyanin accumulation with approximately $60-115 \% \mathrm{com}$ pared to the control while 24-epibrassinolid (epiBL), gibberellic acid $\left(\mathrm{GA}_{3}\right)$ and 6-benzylaminopurine (BAP) had no effect on the anthocyanin accumulation. The simultaneous administration of the PGRs with JA-Me usually resulted in the accumulation of anthocyanins in roots in a manner similar to that caused by JA-Me. PGRs applied to isolated roots did not stimulate anthocyanin accumulation, except for the combination of JA-Me with $50 \mathrm{mg} \cdot \mathrm{L}^{-1}$ IAA.

The results indicate that in $K$. blossfeldiana, the aboveground parts of the plant play an important role in the biosynthesis of anthocyanins in roots.
\end{abstract}

Key words: anthocyanin, plant growth regulators, roots, Kalanchoe blossfeldiana

\section{INTRODUCTION}

Anthocyanins belong to parent class molecules called flavonoids. They occur in all tissues of higher plants, mostly in flowers, fruits but also in leaves, stems and not so often in roots (Chalker-Scott 1999).

Anthocyanins have been the subject of investigation because they play important roles as pollinator attractants, photo-protective agents and in visual attraction in nature. Rao (1990) suggests that root flavonoids play significant roles in regulating root growth and functions, influencing different aspects of nitrogen cycle and protecting the plants against diseases.
The synthesis of anthocyanins is also suggested to be under hormonal control (Weiss et al. 1995, Peng et al. 2011, Nagira et al. 2006).

The growth and development of plants is modulated by interaction between many endogenous factors, including plant growth regulators (PGRs). Changes in the endogenous concentration of the PGRs and the tissue sensitivity in the various plant organs control a wide range of developmental processes. Plant response to hormones is activated after the binding of the hormone to a specific receptor in the cell that initiates a cascade of signalling processes.

Jasmonates (JAs) have been shown to exert inducing effect on the synthesis of anthocyanin, as reported in experiments with many plant species, such 
as soybean seedlings (Glycine max Merr.) (Franceschi \& Grimes 1991), or with stems and leaves of uncooled and cooled tulip bulbs (Tulipa gesneriana L.) (Saniewski et al. 1998). JAs are signalling molecules that play a key role in regulation of plant metabolic processes. These compounds could diffuse to distal parts of the plant via the vapour phase or by intercellular migration, possibly through the phloem. JA and methyl jasmonate (JA-Me) may participate in signal transmission over long distances in the plant (Cheong \& Choi 2003). They are also involved in many processes of the plant life cycle and in adaptation to environmental stress conditions.

Positive effect on the synthesis of anthocyanin has been established also for other hormones, such as gibberellins in petunia flowers (Weiss et al. 1995) and Hyacinthus sepals (Hosokawa 1996). In contrast, gibberellins had inhibiting effect on the synthesis of anthocyanins in maize leaves (Kim et al. 2006). According to El-Kereamy et al. (2003), ethylene positively affected the synthesis of anthocyanin in grape berry skin. Abscisic acid (ABA), depending on the concentration and plant species, stimulated the synthesis of anthocyanins in the skin of grapes (Mori et al. 2005) or inhibited the accumulation of anthocyanins in flowers of petunia (Weiss et al. 1995).

The biosynthesis of anthocyanin in plant tissues either requires light or is enhanced by it. Lightdependent anthocyanin synthesis has been extensively used as a model system for studies of the mechanism of photoregulation of plant development (Mancinelli 1985). Light can penetrate the soil and influence not only root growth, but also several soil microbiological and biochemical processes (Rao 1990). Anthocyanins in the roots may act as a protective antioxidant against stress factors from the environment.

Kalanchoe blossfeldiana, object of our study is a dark green, perennial succulent with scallopedged leaves and large umbels of flower clusters held above the foliage. This is a short day plant. It is interesting that leaves and stem of the plant accumulate significant amounts of anthocyanins as a consequence of photo-periodic response (Neyland et al. 1963).

Saniewski et al. (2003) showed that methyl jasmonate at the concentration of $0.1 \%$ applied in lanolin paste on the middle part of the stem of young plants of K. blossfeldiana grown under natural light conditions greatly stimulated anthocyanins accumulation in the main and lateral stems, both below and above the place of treatment. This effect suggests that JA-Me is transported in $K$. blossfeldiana shoots toward acropetal, as well as basipetal directions. When leaves were removed from the plant of $K$. blossfeldiana almost no anthocyanin formation was observed in stem, after treatment with methyl jasmonate, applied in lanolin paste in the middle part of internodes.

We previously reported a system, in which anthocyanin synthesis was induced in $K$. blossfeldiana roots by methyl jasmonate under natural light conditions in a greenhouse (Góraj \& Saniewski 2009). Seven anthocyanins were documented in the roots of control plants (distilled water) and eight anthocyanins in the roots treated with JA-Me. The total content of anthocyanins in the roots of older plants treated with JA-Me, increased after 4, 8 and 14 days by $6.8,6.0$ and 3.6 times in comparison to the content of anthocyanins in the roots of control plants (water), respectively (Góraj et al. 2011).

The aim of this study was to investigate effects of various concentrations of plant growth regulators (auxins, gibberellin, cytokinin, abscisic acid, brassinosteroid, ethylene), applied alone or simultaneously with methyl jasmonate, on anthocyanin accumulation in roots of intact plants and isolated roots of $K$. blossfeldiana, cultivated in the greenhouse under natural light conditions.

\section{MATERIAL AND METHODS}

The objectives of our study were $K$. blossfeldiana plants of the family Crassulaceae. The plants were grown in a greenhouse at $22 \pm 3{ }^{\circ} \mathrm{C} / 18{ }^{\circ} \mathrm{C}$ (day/night) under natural light conditions. Plants were cultivated in a mixture of soil, peat moss and sand. During the period from January to June, cuttings from old plants were collected and subsequently rooted in distilled water. Then, the roots of the plants were kept at water solutions of plant growth regulators: auxins - IAA $\left(5,50,100 \mathrm{mg} \cdot \mathrm{L}^{-1}\right)$, IBA $\left(5,25,75 \mathrm{mg} \cdot \mathrm{L}^{-1}\right)$, gibberellin $-\mathrm{GA}_{3}(5,25$, $\left.75 \mathrm{mg} \cdot \mathrm{L}^{-1}\right)$, cytokinin - BAP $\left(0.01,0.1,1.0 \mathrm{mg} \cdot \mathrm{L}^{-1}\right)$, 
abscisic acid - ABA (5, 10, $\left.25 \mathrm{mg} \cdot \mathrm{L}^{-1}\right), 24$ epibrassinolid - epiBL $(50,100,300 \mathrm{nM})$, direct precursor of ethylene - ACC $(0.1,1.0 \mathrm{mM})$ used alone and in combination with methyl jasmonate $\left(20 \mathrm{mg} \cdot \mathrm{L}^{-1}\right)$ as a solution. Control plants were kept in distilled water only. Experiments were carried out on whole plants and on isolated roots. The plants were maintained in the greenhouse under natural light conditions.

For each treatment, five to seven plants were used. All analyses were performed in five replicates. The data were subjected to an analysis of variance and Duncan's multiple range test was used for means separation at $\mathrm{p}=0.05$.

\section{Anthocyanin measurements}

Total anthocyanin content was determined using the modified Mancinelli et al. (1988) method. Roots were collected after 14 days from the start of the experiment. Root tissues were extracted overnight in $1 \% \mathrm{HCl}-\mathrm{MeOH}$, at $4{ }^{\circ} \mathrm{C}$ in darkness with occasional shaking. The homogenate was centrifuged at $6000 \times \mathrm{g}$ for $10 \mathrm{~min}$. Absorption of the diluents was measured at $530 \mathrm{~nm}$ (Spectrophotometer Helios- $\varepsilon$ ). Anthocyanin content was calculated as cyanidin-3-glucoside, using 29600 as a molecular extinction coefficient and expressed as $\mu \mathrm{g} \cdot \mathrm{g}^{-1}$ fresh weight (FW).

\section{Ethylene production}

Rooted plants were placed in a solution of JAMe (5 and $\left.20 \mathrm{mg} \cdot \mathrm{L}^{-1}\right)$ and the ACC (0.1, 0.5 and $1.0 \mathrm{mM}$ ) given alone, and in a mixture of these compounds. Control plants were placed in distilled water. After 4 and 14 days, the roots were cut and placed in $10 \mathrm{ml}$ glass vials, sealed with a septum and kept for $2 \mathrm{~h}$. Gas samples were taken from the headspace and injected into a gas chromatograph (Hewlett Packard 58900). Ethylene production was expressed in $\mathrm{nl} \cdot \mathrm{g}^{-1} \cdot \mathrm{h}^{-1}$. The results were statistically analysed, separately for each term of measurement.

\section{RESULTS AND DISCUSSION}

The effects of different exogenous PGRs on anthocyanin synthesis are reported in the literature data. The modulation of hormone sensitivity can cause changes in the synthesis of an unrelated hormone, while in other cases a hormone response gene defines a mode of interaction between two responding pathways (Gazzarrini \& McCourt 2003). Plant growth regulators are also important in controlling anthocyanin biosynthesis.

The production of anthocyanin with participation PGRs inter alia take place in the hairy root cultures in specially designed bioreactors or in cultures of adventitious roots (Betsui et al. 2004; Bae et al. 2012).

Richard et al. (2000) showed that methyl jasmonate as a signal molecule participates in induction of gene transcription leading to L-phenylalanine ammonia-lyase and chalcone synthase, enzymes involved in the synthesis of flavonoids.

It is noted that, no studies were reported on the mechanism of anthocyanin biosynthesis in the roots under influence of methyl jasmonate and on its interaction with PGRs. In this field, only Shimizu et al. (2010) reported that anthocyanin accumulation in the roots of cultured in vitro Gynura bicolor plants was induced by $25-50 \mu \mathrm{M}$ methyl jasmonate treatment. The same anthocyanins were found in the roots as in leaves of fieldgrown plants. This induction was affected by light irradiation and sucrose added to the culture medium.

\section{The effect of PGRs applied to roots of the whole plants alone and combined with JA-Me}

\section{Auxins (IAA and IBA)}

The auxin IAA in all of the applied concentrations slightly stimulated the accumulation of anthocyanins in roots of $K$. blossfeldiana. In the control roots, the content of anthocyanins was $83.74 \mu \mathrm{g} \cdot \mathrm{g}^{-1}$ FW and the highest content was obtained after treatment with IAA at a concentration of $50 \mathrm{mg} \cdot \mathrm{L}^{-1}$ $179.63 \mu \mathrm{g} \cdot \mathrm{g}^{-1} \mathrm{FW}$. IAA applied at a concentration of 5 and $100 \mathrm{mg} \cdot \mathrm{L}^{-1}$ simultaneously with methyl jasmonate $\left(20 \mathrm{mg} \cdot \mathrm{L}^{-1}\right)$ did not affect the accumulation of anthocyanin in roots induced by JA-Me, contrary to IAA concentration of $50 \mathrm{mg} \cdot \mathrm{L}^{-1}$, which stimulated accumulation of anthocyanin (Fig. 1). 


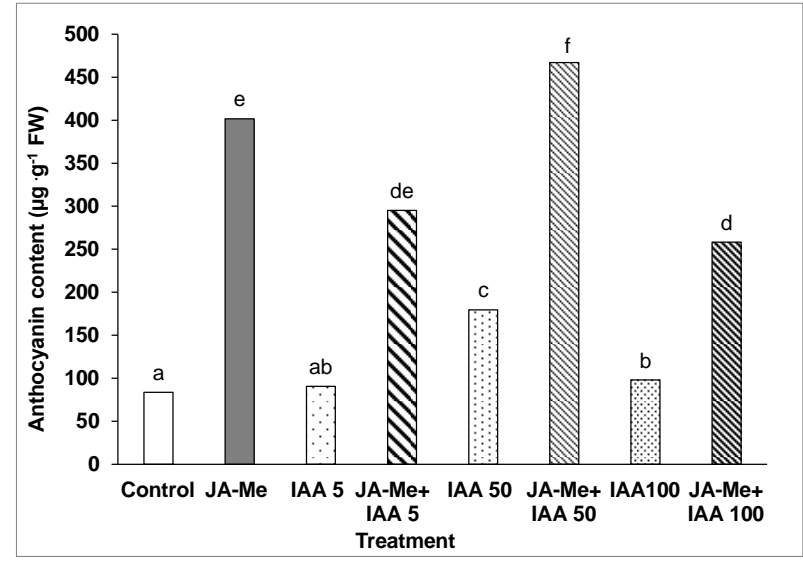

Fig. 1. Effect of IAA applied alone or in combination with JA-Me $\left(20 \mathrm{mg} \cdot \mathrm{L}^{-1}\right)$ to the roots of the whole plants of Kalanchoe blossfeldiana on the content of anthocyanin in roots

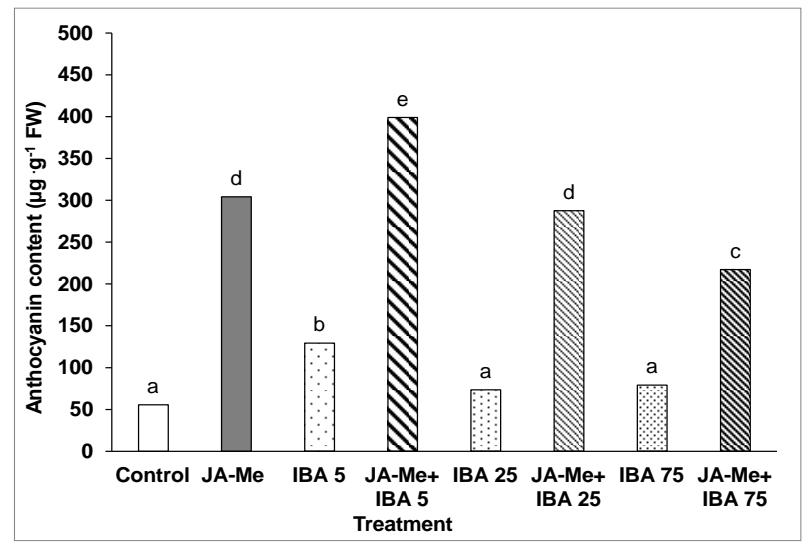

Fig. 2. Effect of IBA applied alone or in combination with JA-Me $\left(20 \mathrm{mg} \cdot \mathrm{L}^{-1}\right)$ to the roots of the whole plants of Kalanchoe blossfeldiana on the content of anthocyanin in roots

Roots of $K$. blossfeldiana treated with IBA at a concentration of $5 \mathrm{mg} \cdot \mathrm{L}^{-1}$ had slightly red pigmentation; however at a concentration of 25 and $75 \mathrm{mg} \cdot \mathrm{L}^{-1}$ the roots were cream-coloured. IBA at a concentration of $5 \mathrm{mg} \cdot \mathrm{L}^{-1}$ applied with JA-Me stimulated accumulation of anthocyanins in the roots, in comparison to the JA-Me treatment alone. However, IBA at a concentration of $25 \mathrm{mg} \cdot \mathrm{L}^{-1} \mathrm{did}$ not influence accumulation of anthocyanin induced by JA-Me. The higher concentration of IBA equals $75 \mathrm{mg} \cdot \mathrm{L}^{-1}$ inhibited anthocyanin accumulation induced by JA-Me (Fig. 2).

Horbowicz et al. (2013), reported that IAA used alone at a low concentrations $10^{-8} \mathrm{M}$ or at $10^{-6}$ and $10^{-4} \mathrm{M}$ in combination with $\mathrm{JA}-\mathrm{Me}\left(10^{-4} \mathrm{M}\right)$ vapours did not affect the level of anthocyanin in cotyledons of buckwheat seedlings. At higher doses of IAA $\left(10^{-6}\right.$ and $\left.10^{-4} \mathrm{M}\right)$, a significant reduction in anthocyanin content was observed.

Another auxin, NAA at a concentration of 200 $\mathrm{mg} \cdot \mathrm{L}^{-1}$ suppressed the anthocyanin content in grape berry skins (Jeong et al. 2004). Low concentration of 2.4-D in the medium enhanced both anthocyanin production and anthocyanin methylation in strawberry suspension culture (Nakamura et al. 1998). Synthesis of anthocyanins was carried out in the hairy roots of Raphanus sativus L. cv. Valentine. Among the different auxin treatments, $1.0 \mathrm{mg} \cdot \mathrm{L}^{-1}$ of 2.4-D resulted in the highest production of anthocyanin (26 times higher), as compared to the control transgenic root cultures of Raphanus sativus (Bae et al. 2012).

\section{Gibberellin (gibberellic acid)}

Figure 3 represents the results of anthocyanin content in the roots of $K$. blossfeldiana treated with gibberellic acid $\left(\mathrm{GA}_{3}\right) . \mathrm{GA}_{3}$ used alone at a concentrations 5,25 and $75 \mathrm{mg} \cdot \mathrm{L}^{-1}$ did not affect the accumulation of anthocyanins in roots of this plant. The roots of the plants treated with $\mathrm{GA}_{3}$ were cream, as in the control. $\mathrm{GA}_{3}$ at a concentration of $5 \mathrm{mg} \cdot \mathrm{L}^{-1}$ applied with JA-Me, caused an increase in the level of anthocyanins induced by JA-Me in the roots. The content of anthocyanins after treatment with JA-Me was $339.93 \mu \mathrm{g} \cdot \mathrm{g}^{-1} \mathrm{FW}$, whereas the JA-Me applied with $\mathrm{GA}_{3}$ at a concentration of $5 \mathrm{mg} \cdot \mathrm{L}^{-1}$ resulted in production of anthocyanins at the level of $422.22 \mu \mathrm{g} \cdot \mathrm{g}^{-1} \mathrm{FW} . \mathrm{GA}_{3}$ at a concentration of $25 \mathrm{mg} \cdot \mathrm{L}^{-1}$ did not affect the accumulation of anthocyanins induced by JA-Me, but at a concentration of $75 \mathrm{mg} \cdot \mathrm{L}^{-1}$ inhibited the accumulation of anthocyanins in this roots.

The application of $\mathrm{GA}_{3}$ used alone $\left(10^{-8}\right.$ and $\left.10^{-6} \mathrm{M}\right)$, and $\mathrm{GA}_{3}\left(10^{-6}\right)$ combined with JA-Me at a concentration of $10^{-4} \mathrm{M}$ did not affect the anthocyanin content in buckwheat cotyledons, whereas the higher dose of this hormone $\left(10^{-4} \mathrm{M}\right)$, in combination with JA-Me $\left(10^{-4} \mathrm{M}\right)$, significantly decreased the content of pigments in buckwheat cotyledons (Horbowicz et al. 2013). The production of anthocyanins was affected by the concentration of gibberellic acid $\left(\mathrm{GA}_{3}\right)$ in flowers of Hyacinthus orientalis. 
The highest concentration of anthocyanins was obtained when the in vitro regenerated flowers were cultured for three weeks at $15{ }^{\circ} \mathrm{C}$ on MS medium, containing $1 \mathrm{mg} \cdot \mathrm{L}^{-1} \mathrm{GA}_{3}$ and $30 \mathrm{~g} \cdot \mathrm{L}^{-1}$ sucrose (Hosokawa et al. 1996). Gibberellic acid at the level of $30 \mu \mathrm{g} \cdot \mathrm{L}^{-1}$ enhanced anthocyanins content and PAL activity in young plants of Fragaria $\times$ ananassa cv. 'Chandler' (Montero et al. 1998).

\section{Cytokinin (6-benzylaminopurine)}

Relationships between anthocyanin content in the roots supplied with methyl jasmonate and 6-benzylaminopurine (BAP) are shown in Figure 4. BAP used at a concentration of $0.01 ; 0.1$ and $1.0 \mathrm{mg} \cdot \mathrm{L}^{-1}$ did not affect the accumulation of anthocyanins in the roots, which was similar as in the control. BAP at a concentration of $0.01 \mathrm{mg} \cdot \mathrm{L}^{-1}$ applied in conjunction with JA-Me, did not influence the accumulation of anthocyanins induced by JA-Me, whereas BAP at 0.1 and $1.0 \mathrm{mg} \cdot \mathrm{L}^{-1}$ inhibited the accumulation of anthocyanins induced by JA-Me.

A stimulatory effect of cytokinins on the synthesis of anthocyanins in tissue cultures or in parts of intact plants was reported in literature data. Fang et al. (1998), reported that BAP supplementation of the suspension culture of Vaccinium palahae in a concentration $20 \mu \mathrm{M}$ increases three times anthocyanin synthesis, and accelerate their production. Anthocyanins production reached a maximum after 16-20 days in cultures containing an optimal kinetin concentration. In intact plants, cytokinins promoted anthocyanin synthesis in petals of Impatiens balsamina (Klein \& Hagen 1961). Cytokinins (BAP $25 \mu \mathrm{M})$ enhanced the response to light in Zea mays, but was not sufficient to induce anthocyanin accumulation in darkness (Piazza et al. 2002).

\section{Abscisic acid}

Abscisic acid (ABA) used individually at a concentration of 5 to $25 \mathrm{mg} \cdot \mathrm{L}^{-1}$ slightly stimulated the accumulation of anthocyanins (Fig. 5). The highest content of anthocyanins in the roots of the plants were obtained after treatment with $\mathrm{ABA}$ at $10 \mathrm{mg} \cdot \mathrm{L}^{-1}$. The combined treatment with methyl jasmonate $\left(20 \mathrm{mg} \cdot \mathrm{L}^{-1}\right)$ and $\mathrm{ABA}$ at $5 \mathrm{mg} \cdot \mathrm{L}^{-1} \mathrm{re}-$ sulted in increased content of anthocyanins in the roots, compared to the treatment with JA-Me alone. $\mathrm{ABA}$ at a concentration of $10 \mathrm{mg} \cdot \mathrm{L}^{-1}$ did not affect the accumulation of anthocyanins induced by

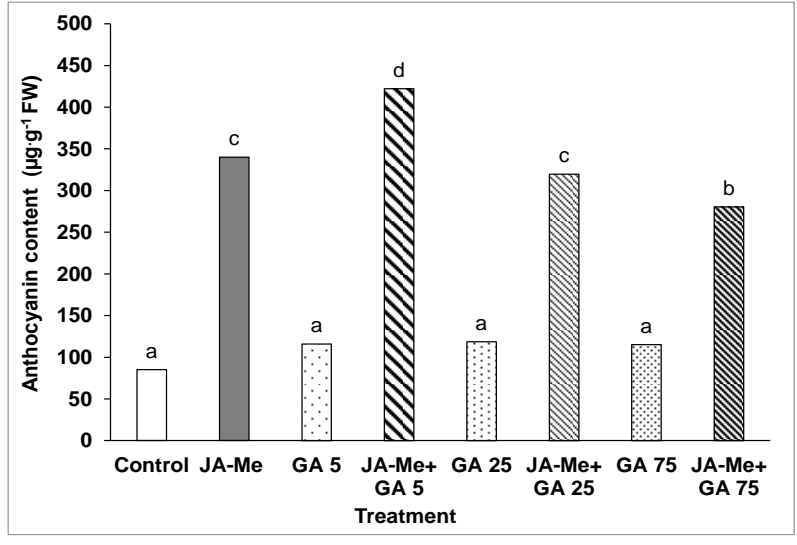

Fig. 3. Effect of $\mathrm{GA}_{3}$ applied alone or in combination with JA-Me $\left(20 \mathrm{mg} \cdot \mathrm{L}^{-1}\right)$ to the roots of the whole plants of Kalanchoe blossfeldiana on the content of anthocyanin in roots

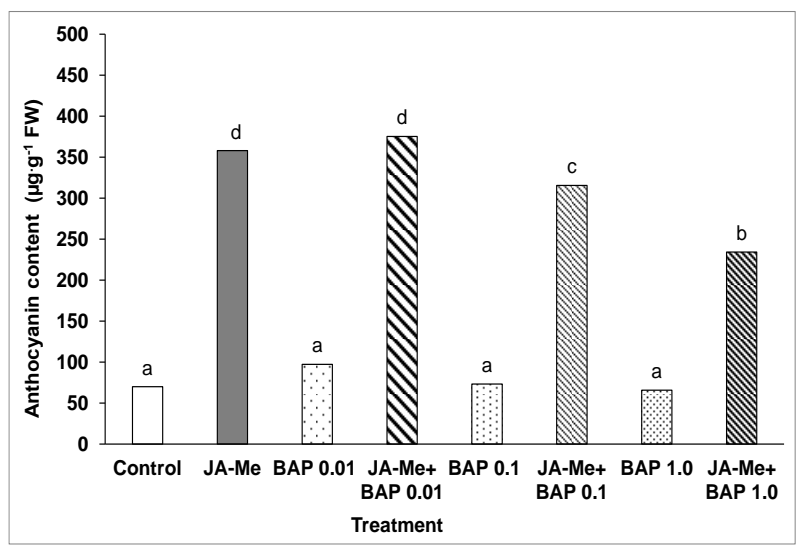

Fig. 4. Effect of BAP applied alone or in combination with JA-Me $\left(20 \mathrm{mg} \cdot \mathrm{L}^{-1}\right)$ to the roots of the whole plants of Kalanchoe blossfeldiana on the content of anthocyanin in roots

JA-Me, but at $25 \mathrm{mg} \cdot \mathrm{L}^{-1}$ inhibited their accumulation in the roots (Fig. 5).

Endogenous ABA may play a role in strawberry fruit colour development during ripening through upregulation of ethylene production and PAL activity (Jiang \& Joyce 2003). ABA increases the activity of PAL, a key regulatory enzyme of anthocyanin biosynthesis, and promotes senescence of rice leaves (Hung \& Kao 2004). Exogenous ABA induced anthocyanin synthesis in regenerating Torenia fournieri shoots in the medium containing a low concentration of sucrose (1.5\%) (Nagira et al. 2006). Application of ABA (at 0.01 to $1 \mu \mathrm{M}$ ) to non-chlorophyllous corn leaf segments had a stimulatory effect on anthocyanin accumulation. However, the higher 
ABA rate decreased pigment accumulation because of the disintegration of cell membranes (Kim et al. 2006). On the other hand, ABA at high concentration reduced root growth and induced a significant decrease of the anthocyanin level in Zea mays. Removal of the cap, which produced or released ABA, enhanced the anthocyanin concentration (Pilet \& Takahashi 1979). In roots of Impatiens glandulifera cv. Royle, ABA can inhibit dormancy break and anthocyanin synthesis in the root caps (Mumford 1990).

\section{Brassinosteroids (24-epibrassinolide)}

The effect of 24-epibrassinolide (epiBL) and its interaction with JA-Me on anthocyanin accumulation in roots is shown in Figure 6. It has been found that epiBL applied individually at concentrations of 50, 100 and $300 \mathrm{nM}$ did not affect the accumulation of anthocyanins in the roots of plants. Roots were creamy as in the control (Fig. 6). EpiBL at a concentration of $50 \mathrm{nM}$ applied together with JA-Me did not influence on the accumulation of anthocyanins induced by JA-Me, but used at a concentration of $100 \mathrm{nM}$ increased the anthocyanin accumulation in the roots induced by JA-Me, whereas a concentration of $300 \mathrm{nM}$ had the inhibitory effect on the accumulation of anthocyanins induced by JA-Me.

Cevahir et al. (2008) showed that 24-epiBL used at concentrations of $10^{-5}, 10^{-7}, 10^{-9} \mathrm{M}$ greatly increased accumulation of anthocyanin's in hypocotyl of Glycine max L. seedlings grown in a light by $87,147,282 \%$, respectively.

The total anthocyanin content in brassinosteroid (BR) treated grapes was higher than in a control and the $0.4 \mathrm{mg} \cdot \mathrm{L}^{-1} \mathrm{BR}$ was the most effective concentration for anthocyanin synthesis (Luan et al. 2013).

EpiBL $(1 \mu \mathrm{M})$ applicated with methyl jasmonate $(50 \mu \mathrm{M})$ causes increase of anthocyanin content in Arabidopsis plants, in comparison to content in plants treated with methyl jasmonate only. Inhibitor of BR biosynthesis - brassinazole inhibits anthocyanin accumulation induced by jasmonic acid, which indicated that brassinosteroids play a very important function in mechanism of anthocyanins biosynthesis induced by jasmonates (Peng et al. 2011).
On the other hand, Çăg et al. (2007) demonstrated the inhibitory effect of brassinosteroids on anthocyanin biosynthesis. The pigment contents in red cabbage cotyledons incubated in epiBL solution at 10 and $0.1 \mu \mathrm{M}$ epiBL decreased by $52 \%$ and $21 \%$, respectively, but did not change at $0.001 \mu \mathrm{M}$ epiBL in comparison with control.

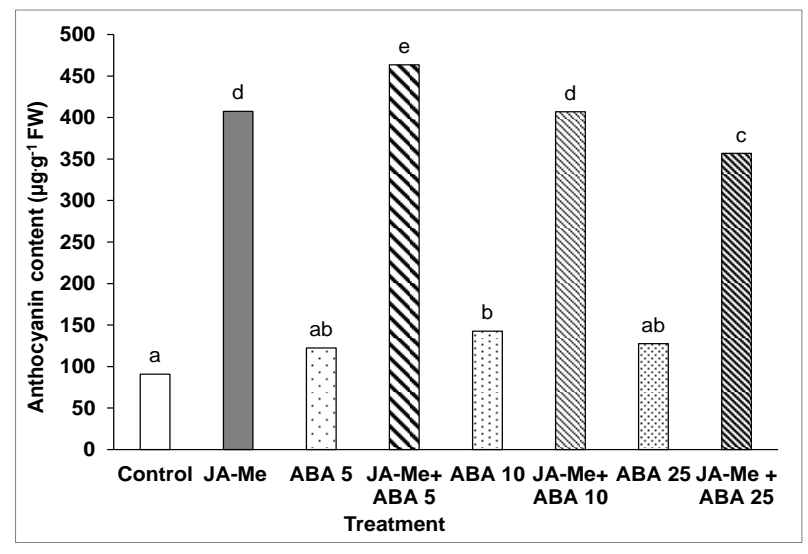

Fig. 5. Effect of ABA applied alone or in combination with JA-Me $\left(20 \mathrm{mg} \cdot \mathrm{L}^{-1}\right)$ to the roots of the whole plants of Kalanchoe blossfeldiana on the content of anthocyanin in roots

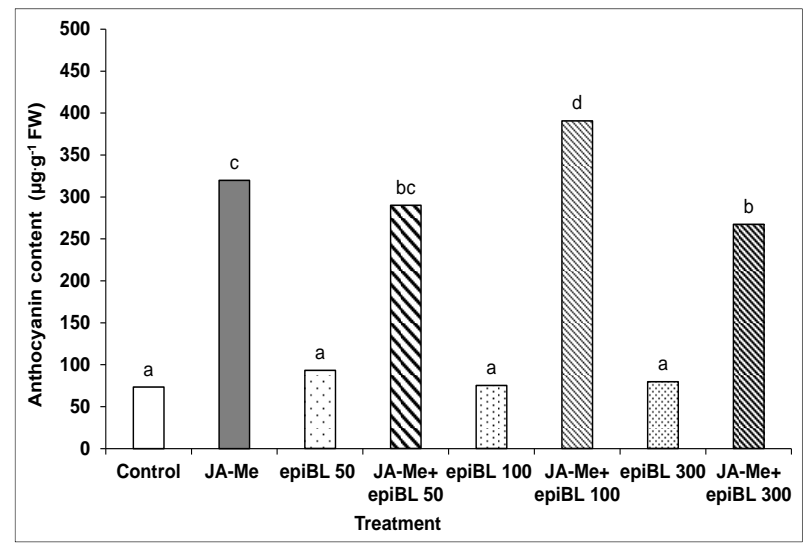

Fig. 6. Effect of epiBL applied alone or in combination with JA-Me $\left(20 \mathrm{mg} \cdot \mathrm{L}^{-1}\right)$ to the roots of the whole plants of Kalanchoe blossfeldiana on the content of anthocyanin in roots

\section{ACC (1-aminocyclopropane-1-carboxylic acid)}

In our study, the precursor of ethylene biosynthesis, ACC, used at a concentration of 0.1 and $1.0 \mathrm{mM}$ did not affect the accumulation of anthocyanins in the roots. The roots of the control plants contained 
$95.27 \mu \mathrm{g} \cdot \mathrm{g}^{-1} \mathrm{FW}$ of anthocyanins, whereas treatment with 0.1 and $1.0 \mathrm{mM}$ decreased the concentration of anthocyanins to 64.69 and $60.86 \mu \mathrm{g} \cdot \mathrm{g}^{-1} \mathrm{FW}$ (Fig. 7). ACC at a 0.1 and $1.0 \mathrm{mM}$ applied with JAMe inhibited anthocyanin accumulation in the roots of $K$. blossfeldiana induced by JA-Me. Anthocyanin content in the roots of the plants treated with methyl jasmonate was $396.58 \mu \mathrm{g} \cdot \mathrm{g}^{-1} \mathrm{FW}$ and treated with $\mathrm{ACC}$ at a $1.0 \mathrm{mM}$ together with JA-Me was $138.50 \mu \mathrm{g} \cdot \mathrm{g}^{-1} \mathrm{FW}$ (Fig. 7).

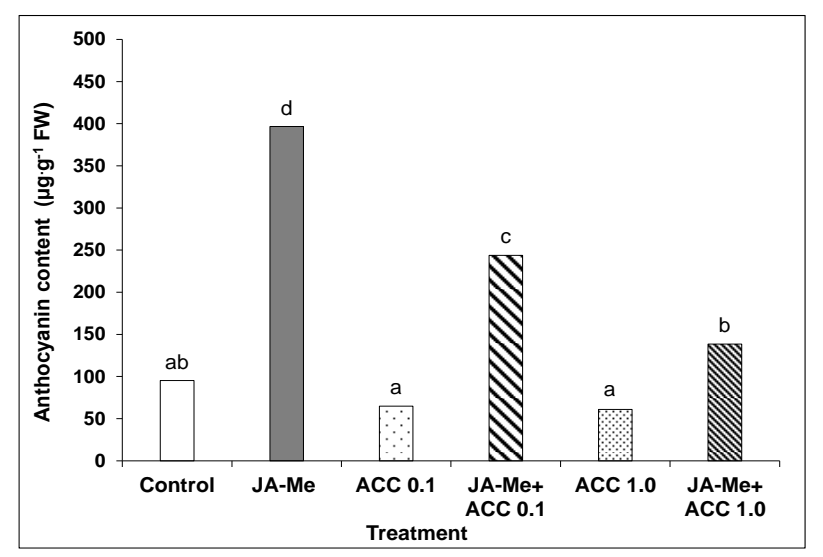

Fig. 7. Effect of individual $\mathrm{ACC}(0.1,1.0 \mathrm{mM})$ treatment or combined with JA-Me $\left(20 \mathrm{mg} \cdot \mathrm{L}^{-1}\right)$ on the content of anthocyanin in roots of Kalanchoe blossfeldiana

The production of ethylene in the roots of control plants after 4 and 14 days was low and did not exceed $10 \mathrm{nl} \cdot \mathrm{g}^{-1} \cdot \mathrm{h}^{-1}$ (Fig. 8). The use of JA-Me at 5 and $20 \mathrm{mg} \cdot \mathrm{L}^{-1}$ did not affect the ethylene evolution. When the roots were placed in solutions of ACC $(0.1,0.5$ and $1.0 \mathrm{mM})$, the production of ethylene was significantly higher $\left(23-44 \mathrm{nl} \cdot \mathrm{g}^{-1} \cdot \mathrm{h}^{-1}\right)$, compared to control plants. After 4 days of the treatment, JA-Me at a concentration of $5 \mathrm{mg} \cdot \mathrm{L}^{-1}$ applied together with ACC stimulated the production of ethylene at all of the used ACC concentrations. After 14 days JA-Me stimulated the production of ethylene, but only at the highest concentration of ACC $(1.0 \mathrm{mM})$. JA-Me at a $20 \mathrm{mg} \cdot \mathrm{L}^{-1}$ with $\mathrm{ACC}$, increased the ethylene production at all the used ACC concentrations, after 4 and 14 days (Fig. 8).

Anthocyanin synthesis can also be enhanced by exogenous ethylene or the ethylene-releasing compound, ethephon (2-chloroethyl phosphonic acid) (Gómez-Cordovés et al. 1996), possibly by increasing enzymatic activity in the phenyl-propanoid pathway (Li et al. 2002). Application of aminoethoxyvinylglycine (AVG), an ethylene synthesis inhibitor, reduces anthocyanin accumulation (Wang \& Dilley 2001). Rudell and Mattheis (2008), reported that treatment with JA-Me alone and with JA$\mathrm{Me}+$ ethylene enhanced the major anthocyanins content in apple fruit.

Shimizu et al. (2010) showed that induction of anthocyanins accumulation in shoots and roots of Gynura bicolor plants was not affected by ACC. This indicates that ethylene might not be involved in the induction of anthocyanin accumulation directly or might not act as a positive inducer of anthocyanin biosynthesis in G. bicolor.

Saniewski et al. (1997) reported that JA-Me can increase ethylene production in various organs and intact plants of many species by stimulating activities of ACC synthase and ACC oxidase.

In both dendrobium and petunia flowers, the JA-Me induced increase in ethylene production and 1-aminocyclopropane-1-carboxylic acid content. Aminooxyacetic acid (inhibitor of ACC-synthase) and silver-thiosulfate (inhibitor of ethylene action) completely inhibited the effects of JA-Me. It was also found that JA-Me enhances petunia and dendrobium flower senescence via the promotion of ACC and ethylene production (Porat et al. 1993).

\section{The effect of PGRs applied to the isolated roots alone or in combination with JA-Me}

The plant growth regulators applied to isolated roots did not affect accumulation of anthocyanins in the roots. The treated roots were creamy, similar to the control. The addition of JA-Me did not affect the accumulation of anthocyanins, except for IAA (Table 1).

However, the above-ground part of plant is not needed for the production of anthocyanins in adventitious root cultures of Raphanus sativus L. cv. Peking Koushin. Adventitious roots cultured in $1 / 2 \mathrm{MS}$ liquid medium supplemented with IBA at a concentration of $0.5 \mathrm{mg} \cdot \mathrm{L}^{-1}$ for four weeks, at $25^{\circ} \mathrm{C}$ under $14 \mathrm{~h} /$ day light conditions, produced high amounts of anthocyanin (Betsui et al. 2004). 


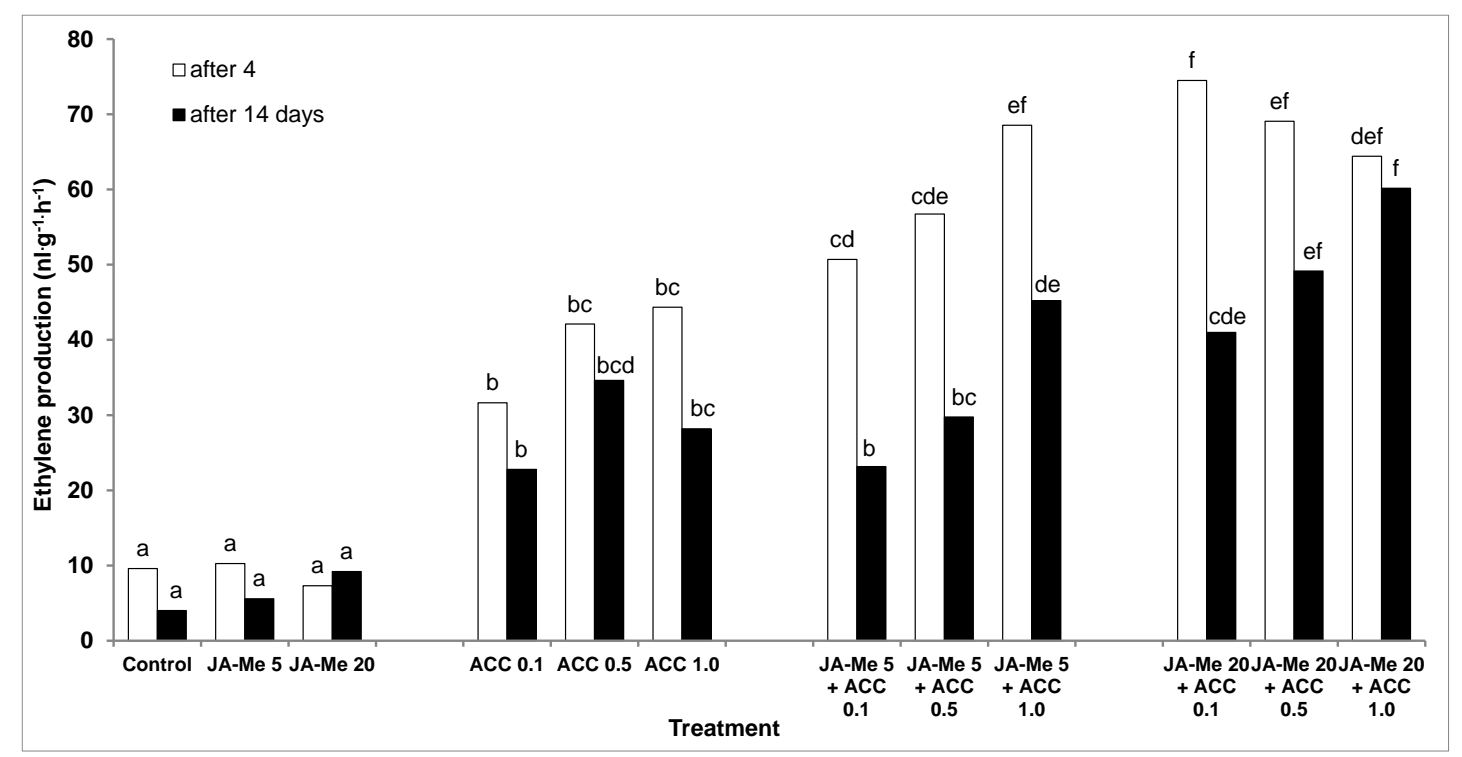

Fig. 8. Effect of JA-Me and ACC applied alone or in combination to the roots of the whole plants of Kalanchoe blossfeldiana on ethylene production in roots The results were statistically analysed separately for each term of measurement.

Table 1. Effect of PGRs applied to the isolated roots of Kalanchoe blossfeldiana alone or in combination with $\mathrm{JA}-\mathrm{Me}$ on the anthocyanin formation in roots

\begin{tabular}{ll}
\hline \multicolumn{1}{c}{ Treatment } & $\begin{array}{l}\text { Anthocya- } \\
\text { nin content } \\
\left(\mu \mathrm{g} \cdot \mathrm{g}^{-1} \mathrm{FW}\right)\end{array}$ \\
\hline Control & $37.94 \mathrm{bcd}$ \\
$\mathrm{JA}-\mathrm{Me} 20 \mathrm{mg} \cdot \mathrm{L}^{-1}$ & $58.93 \mathrm{de}$ \\
$\mathrm{IAA} 50 \mathrm{mg} \cdot \mathrm{L}^{-1}$ & $37.31 \mathrm{abc}$ \\
$\mathrm{JA}-\mathrm{Me} 20 \mathrm{mg} \cdot \mathrm{L}^{-1}+\mathrm{IAA} 50 \mathrm{mg} \cdot \mathrm{L}^{-1}$ & $60.69 \mathrm{e}$ \\
$\mathrm{GA} 3 \mathrm{mg} \cdot \mathrm{L}^{-1}$ & $35.70 \mathrm{abc}$ \\
$\mathrm{JA}-\mathrm{Me} 20 \mathrm{mg} \cdot \mathrm{L}^{-1}+\mathrm{GA} 3 \mathrm{mg} \cdot \mathrm{L}^{-1}$ & $21.70 \mathrm{a}$ \\
$\mathrm{BAP} 0.1 \mathrm{mg} \cdot \mathrm{L}^{-1}$ & $34.53 \mathrm{abc}$ \\
$\mathrm{JA}-\mathrm{Me} 20 \mathrm{mg} \cdot \mathrm{L}^{-1}+\mathrm{BAP} 0.1 \mathrm{mg} \cdot \mathrm{L}^{-1}$ & $22.96 \mathrm{ab}$ \\
$\mathrm{epiBL} 300 \mathrm{nM}$ & $39.66 \mathrm{bcd}$ \\
$\mathrm{JA}-\mathrm{Me} 20 \mathrm{mg} \cdot \mathrm{L}^{-1}+\mathrm{epiBL} 300 \mathrm{nM}$ & $24.23 \mathrm{ab}$ \\
ABA $10 \mathrm{mg} \cdot \mathrm{L}^{-1}$ & $38.68 \mathrm{~cd}$ \\
$\mathrm{JA}-\mathrm{Me} 20 \mathrm{mg} \cdot \mathrm{L}^{-1}+\mathrm{ABA} 10 \mathrm{mg} \cdot \mathrm{L}^{-1}$ & $42.00 \mathrm{~cd}$ \\
\hline
\end{tabular}

\section{CONCLUSION}

In this study, the treatments of the roots of whole Kalanchoe blossfeldiana plants with PGRs, showed that methyl jasmonate is the most important factor inducing anthocyanins accumulation in these roots under natural light condition in a greenhouse. The above-ground part of the plant plays an important role in the biosynthesis of anthocyanins in roots. The contents of anthocyanins in roots of whole $K$. blossfeldiana were also higher after treatments with IAA at a concentration of $50 \mathrm{mg} \cdot \mathrm{L}^{-1}$, IBA at $5 \mathrm{mg} \cdot \mathrm{L}^{-1}$ and $\mathrm{ABA}$ at $10 \mathrm{mg} \cdot \mathrm{L}^{-1}$. These PGRs increased anthocyanins accumulation by 60 to $115 \%$, compared to the control. Other plant growth regulators $\left(\mathrm{GA}_{3}, \mathrm{BAP}\right.$, epiBL) tested individually under the same conditions as the JA-Me did not affect the formation of anthocyanins in the roots of $K$. blossfeldiana. It should be mentioned that highest anthocyanins elicitation in roots were obtained using JA-Me in combination with IAA 50, ABA 5 or $\mathrm{GA}_{3} 5 \mathrm{mg} \cdot \mathrm{L}^{-1}$.

\section{REFERENCES}

Bae H., Kim Y.B., Park N.I., Kim H.H., Kim Y.S., Lee M.Y., Park S.U. 2012. Agrobacterium rhizogenesmediated genetic transformation of radish (Raphanus sativus L. cv. Valentine) for accumulation of anthocyanin. Plant Omics Journal 5: 381-385.

Betsui F., Tanaka-Nishikawa N., Shimomura K. 2004. Anthocyanin production in adventitious root cultures of Raphanus sativus L. cv. Peking Koushin. Plant Biotechnol. 21: 387-391. DOI: 10.5511/plantbiotechnology.21.387.

Çağ S., Gören-Sağlam N., Çingil-Bariş Ç., Kaplan E. 2007. The effect of different concentration of epibrassinolide on chlorophyll, protein and anthocyanin content and peroxidase activity in excised red- 
cabbage (Brassica oleracea L.) cotyledons. Biotechnol. Biotechnol. Eq. 21: 422-425.

Cevahir G., Yentür S., Eryilmaz F., Yilmazer N. 2008. Influence of brassinosteroids on pigment content of Glycine max L. (soybean) grown in dark and light. J. Appl. Biol. Sci. 2: 23-28.

Chalker-Scott L. 1999. Environmental significance of anthocyanin in plants stress responses. Photochem. Photobiol. 70: 1-9. DOI: 10.1111/j.17511097.1999.tb01944.x.

Cheong J-J., Choi Y.D. 2003. Methyl jasmonate as a vital substance in plants. Trends in Genetics 19(7): 409 413. DOI: 10.1016/S0168-9525(03)00138-0.

El-Kereamy A., Chervin C., Roustan J.-P., Cheynier V., Souquet J.-M., Moutounet M., et al. 2003. Exogenous ethylene stimulates the long-term expression of genes related to anthocyanin biosynthesis in grape berries. Physiol. Plant. 119: 175-182. DOI: 10.1034/j.1399-3054.2003.00165.x.

Fang Y., Smith M.A.L., Pépin M.-F. 1998. Benzyladenine restores anthocyanin pigmentation in suspension cultures of wild Vaccinium pahalae. Plant Cell Tiss. Org. Cult. 54: 113-122.

Franceschi V.R., Grimes G.D. 1991. Induction of soybean vegetative storage proteins and anthocyanins by low-level atmospheric methyl jasmonate. Proc. Natl. Acad. Sci. USA 88: 6745-6749. DOI: 10.1073/pnas.88.15.6745.

Gazzarrini S., McCourt P. 2003. Cross-talk in plant hormone signalling: what Arabidopsis mutants are telling us. Ann. Bot. 91: 605-612. DOI: 10.1093/aob/mcg064.

Gómez-Cordovés C., Varela F., Larrigaudiere C., Vendrell M. 1996. Effect of ethephon and seniphos treatments on the anthocyanin composition of 'Starking' apples. J. Agric. Food Chem. 44: 3449-3452.

Góraj J., Saniewski M. 2009. Methyl jasmonate induces anthocyanins accumulation in roots of Kalanchoe blossfeldiana. 8th International Conference "Ecophysiological Aspects of Plant Responses to Stress Factors", September 16-20, 2009, Cracow, Poland, Book of Abstracts, p. 101.

Góraj J., Stochmal A., Oleszek W., Mołdoch J., Saniewski M. 2011. Elicitation of anthocyanins production in the roots of Kalanchoe blossfeldiana by methyl jasmonate. "II Conference of Bioactive Plant Compounds Structural and Applicative Aspects", September $12^{\text {nd }}-14^{\text {nd }}, 2011$, Puławy, Poland. Abstracts Book, Poster P5.21, p. 46.

Horbowicz M., Kosson R., Saniewski M., Mitrus J., Koczkodaj D. 2013. Effects of simultaneous use of methyl jasmonate with other plant hormones on the level of anthocyanins and biogenic amines in seedlings of common buckwheat (Fagopyrum esculentum Moench). Acta Agrobot. 66: 17-26. DOI: 10.5586/aa.2013.003.

Hosokawa K., Fukunaga Y., Fukushi E., Kawabata J. 1996. Production of acylated anthocyanins by blue flowers of Hyacinthus orientalis regenerated in vitro. Phytochemistry 41: 1531-1533.

Hung K.T., Kao C.H. 2004. Hydrogen peroxide is necessary for abscisic acid-induced senescence of rice leaves. J. Plant Physiol. 161: 1347-1357. DOI: 10.1016/j.jplph.2004.05.011.

Jeong S.T., Goto-Yamamoto N., Kobayashi S., Esaka M. 2004. Effects of plant hormones and shading on the accumulation of anthocyanin and expression of anthocyanin biosynthesis genes in grape berry skins. Plant Sci. 167: 247-252. DOI: 10.1016/j.plantsci.2004.03.021.

Jiang Y., Joyce D.C. 2003. ABA effects on ethylene production, PAL activity, anthocyanin and phenolic contents of strawberry fruit. Plant Growth Regul. 39: 171-174.

Kim J.S., Lee B.H., Kim S.H., Oh K.H., Cho K.Y. 2006. Response to environmental and chemical signals for anthocyanin biosynthesis in nonchlorophyllous corn (Zea mays L.) leaf. J. Plant Biol. 49: 16-25.

Klein A.O., Hagen C.W. Jr. 1961. Anthocyanin production in detached petals of Impatiens balsamina L. Plant Physiol. 36: 1-9. DOI: 10.1104/pp.36.1.1

Li Z.H., Gemma H., Iwahori S. 2002. Stimulation of 'Fuji' apple skin color by ethephon and phosphorus-calcium mixed compounds in relation to flavonoid synthesis. Sci. Hortic. 94: 193-199. DOI: 10.1016/S0304-4238(01)00363-6.

Luan L.-Y., Zhang Z.-W., Xi Z.-M., Huo S.-S., Ma L.-N. 2013. Brassinosteroids regulate anthocyanin biosynthesis in the ripening of grape berries. S. Afr. J. Enol. Vitic. 34: 196-203.

Mancinelli A.L. 1985. Light-dependent anthocyanin synthesis: A model system for the study of plant photomorphogenesis. Bot. Rev. 51: 107-157. DOI: 10.1007/BF02861059.

Mancinelli A.L., Hoff A.M., Cottrell M. 1988. Anthocyanin production in Chl-rich and Chl-poor seedlings. Plant Physiol. 86: 652-654. DOI: 10.1104/pp.86.3.652.

Montero T., Mollà E., Martín-Cabrejas M.A., López-Andréu F.J. 1998. Effects of gibberellic acid $\left(\mathrm{GA}_{3}\right)$ on strawberry PAL (phenylalanine ammonia-lyase) and TAL (tyrosine ammonia-lyase) enzyme activities. J. 
Sci. Food Agric. 77: 230-234. DOI: 10.1002/(SICI)1097-0010(199806)77:2<230::AIDJSFA27>3.0.CO;2-G.

Mori K., Saito H., Goto-Yamamoto N., Kitayama M., Kobayashi S., Sugaya S., et al. 2005. Effect of abscisic acid treatment and night temperatures on anthocyanin composition in Pinot noir grapes. Vitis 44: 161-165.

Mumford P.M. 1990. Dormancy break in seeds of Impatiens glandulifera Royle. New Phytol. 115: 171-175. DOI: 10.1111/j.1469-8137.1990.tb00935.x.

Nagira Y., Ikegami K., Koshiba T., Ozeki Y. 2006. Effect of ABA upon anthocyanin synthesis in regenerated torenia shoots. J. Plant Res. 119: 137-144. DOI: 10.1007/s10265-005-0256-9.

Nakamura M., Seki M., Furusaki S. 1998. Enhanced anthocyanin methylation by growth limitation in strawberry suspension culture. Enzyme Microb. Technol. 22(5): 404-408. DOI: 10.1016/S01410229(97)00213-5.

Neyland M., Ng Y.L., Thimann K.V. 1963. Formation of anthocyanin in leaves of Kalanchoe blossfeldiana a photoperiodic response. Plant Physiol. 38: 447 451. DOI: $10.1104 / p p .38 .4 .447$.

Peng Z., Han Ch., Yuan L., Zhang K., Huang H., Ren Ch. 2011. Brassinosteroid enhances jasmonate-induced anthocyanin accumulation in Arabidopsis seedlings. J. Integr. Plant Biol. 53: 632-640. DOI: 10.1111/j.1744-7909.2011.01042.x.

Piazza P., Procissi A., Jenkins G.I., Tonelli C. 2002. Members of the $\mathrm{cp} 1 / \mathrm{pl} 1$ regulatory gene family mediate the response of maize aleurone and mesocotyl to different light qualities and cytokinins. Plant Physiol. 128: 1077-1086. DOI: 10.1104/pp.010799.

Pilet P.E., Takahashi P. 1979. Effect of abscisic acid on anthocyanin content in light exposed roots. Plant Sci. Lett. 17: 1-6. DOI: 10.1016/0304-4211(79)90101-9.

Porat R., Borochov A., Halevy A.H. 1993. Enhancement of petunia and dendrobium flower senescence by jasmonic acid methyl ester is via the promotion of ethylene production. Plant Growth Regul. 13: 297-301.
Rao A.S. 1990. Root Flavonoids. Bot. Rev. 56: 1-84.

Richard S., Lapointe G., Rutledge R.G., Séguin A. 2000. Induction of chalcone synthase expression in white spruce by wounding and jasmonate. Plant Cell Physiol. 41: 982-987. DOI: 10.1093/pcp/pcd017.

Rudell D.R., Mattheis J.P. 2008. Synergism exists between ethylene and methyl jasmonate in artificial light-induced pigment enhancement of 'Fuji' apple fruit peel. Postharvest Biol. Technol. 47: 136-140. DOI: 10.1016/j.postharvbio.2007.05.021.

Saniewski M. 1997. The role of jasmonates in ethylene biosynthesis. In: Kanellis A.K., Chang C., Grierson D. (Eds.), Biology and Biotechnology of the Plant Hormone Ethylene. Kluwer Academic Publishers, Dordrecht, Boston, London, pp. 39-45. DOI: 10.1007/978-94-011-5546-5_6

Saniewski M., Horbowicz M., Puchalski J., Ueda J. 2003. Methyl jasmonate stimulates the formation and accumulation of anthocyanins in Kalanchoe blossfeldiana. Acta Physiol. Plant. 25: 143-149. DOI: 10.1007/s11738-003-0047-7

Saniewski M., Miszczak A., Kawa-Miszczak L., Węgrzynowicz-Lesiak E., Miyamoto K., Ueda J. 1998. Effects of methyl jasmonate on anthocyanin accumulation, ethylene production, and $\mathrm{CO}_{2}$ evolution in uncooled and cooled tulip bulbs. J. Plant Growth Regul. 17: 33-37. DOI: 10.1007/PL00007009

Shimizu Y., Maeda K., Kato M., Shimomura K. 2010. Methyl jasmonate induces anthocyanin accumulation in Gynura bicolor cultured roots. In Vitro Cell. Dev. Biol.-Plant 46: 460-465. DOI: 10.1007/s11627-010-9294-7.

Wang Z.Y., Dilley D.R. 2001. Aminoethoxyvinylglycine, combined with ethephon, can enhance red color development without over-ripening apples. HortScience 36: 328-331.

Weiss D., Van der Luit A., Knegt E., Vermeer E., Mol J.N.M, Kooter J.M. 1995. Identification of endogenous gibberellins in petunia flower, induction of anthocyanin biosynthesis gene expression and the antagonistic effect of abscisic acid. Plant Physiol. 107: 695-702. 